Вестник ВГУ. Серия: Право

УДК 343.21

DOI https://doi.org/10.17308/vsu.proc.law.2020.3/2991

\title{
О ПРИМЕНЕНИИ УГОЛОВНО-ПРАВОВЫХ ЗАПРЕТОВ, СКОНСТРУИРОВАННЫХ С ИСПОЛЬЗОВАНИЕМ АДМИНИСТРАТИВНОЙ ПРЕЮДИЦИИ
}

\author{
С. А. Маркунцов \\ Национальный исследовательский университет \\ "Высшая школа эконолики» (2. Москва) \\ Поступила в редакцию 18 июля 2019 г.
}

\begin{abstract}
Аннотация: рассматриваются вопросы поэтапного введения и приленения уголовно-правовых запретов, сконструированных с использованиел адлинистративной преюдиции. В зависилости от особенностей правоприленительной практики предлагается их авторская классификация. Более детально анализируются сложности приленения запрета розничной продажи несовершеннолетнил алкогольной продукиии.

Ключевые слова: уголовно-правовой запрет, адлинистративная преюдииия, Уголовный кодекс РФ, правоприленительная практика, розничная продажа несовершеннолетним алкогольной продукиии.
\end{abstract}

\begin{abstract}
: the article deals with the issues of the phased introduction and application of criminal law prohibitions designed using administrative prejudice. Depending on the specifics of the law enforcement practice, their author's classification is proposed. The complexity of the prohibition of retail sales of alcohol to minors is analyzed in more detail.

Key words: criminal law prohibition, administrative prejudice, Criminal Code of the Russian Federation, law enforcement practice, retail sale of alcoholic beverages to minors.
\end{abstract}

$m$

Уголовно-правовые запреты, сконструированные с использованием административной преюдиции, существуют в действующем российском уголовном законе немногим более 10 лет. В данном случае речь идет о «классическом» варианте административной преюдиции, т. е. не рассматриваются случаи так называемой преюдиции в "скрытом» виде, которые выделяются некоторыми учеными, в частности А. В. Иванчиным, Э. Л. Сидоренко и др. Конструктивной особенностью уголовно-правовых запретов со «скрытой» преюдицией является наличие признаков злостности либо неоднократности совершения деяний (в качестве примера приведем запреты, содержащиеся в ст. 154 «Незаконное усыновление (удочерение)», 180 «Незаконное использование средств индивидуализации товаров (работ, услуг)» УК РФ)ํ.

${ }^{1}$ Об этом, например, см.: Иванчин A. B. О целесообразности построения составов преступлений с административной преюдицией // Библиотека криминалиста. 2013. № 2. С. 99 ; Сидоренко Э. Л. Особенности квалификации преступлений преюдиционного характера // Общество и право. 2016. № 1. С. 61 ; и др.

(C) Маркунцов С. А., 2020 


\section{Уголовное право. Уголовный процесс. Криминалистика}

За указанный период введение запретов, сконструированных с административной преюдицией, в Уголовный кодекс Российской Федерации (далее - УК РФ) происходило с различной степенью интенсивности и носило цикличный характер. Если с июля 2009 г. по июль 2011 г. в УК РФ было добавлено только два таких запрета, содержащихся в ст. 178 (данная редакция статьи введена Федеральным законом от 29 июля 2009 г. № 216-ФЗ) и ст. 151.1 УК РФ (введена Федеральным законом от 21 июля 2011 г. № 253-ФЗ), то в период с июля 2014 г. по июль 2016 г. эта деятельность существенно активизировалась и административная преюдиция появилась еще в восьми уголовно-правовых запретах, закрепленных в ст. 212.1 (введена Федеральным законом от 21 июля 2014 г. № 258-Ф3), 314.1 (ч. 2) (данная редакция соответствующей части статьи введена Федеральным законом от 31 декабря 2014 г. № 514-ФЗ), 264.1 (введена Федеральным законом от 31 декабря 2014 г. № 528-Ф3), 284.1 (введена Федеральным законом от 23 мая 2015 г. № 129-ФЗ), 215.4 (введена Федеральным законом от 30 декабря 2015 г. № 441-Ф3), 116.1, 157, 158.1 (в указанных редакциях статьи введены в соответствии с Федеральным законом от 3 июля 2016 г. № 323-ФЗ) УК РФ. Отметим, что согласно Федеральному закону от 8 марта 2015 г. № 45-ФЗ ст. 178 УК РФ была изложена в новой редакции уже без использования административной преюдиции. После июля 2016 г. введение уголовно-правовых запретов с конструкцией административной преюдиции временно затормозилось. Возможно, отчасти это было связано с тем, что активно стал обсуждаться вопрос введения в уголовно-правовую «материю» института уголовного проступка и последующим появлением проекта федерального закона «О внесении изменений в Уголовный кодекс Российской Федерации и Уголовно-процессуальный кодекс Российской Федерации в связи с введением понятия уголовного проступка», по вопросу внесения которого в Государственную Думу Федерального Собрания РФ принято постановление Пленума Верховного Суда РФ от 31 октября 2017 г. № $42^{2}$. По мнению отдельных ученых, проблема административной преюдиции прямо связана с проблемой введения уголовного проступка. В частности, в ходе обсуждения вышеуказанного законопроекта Р. О. Долотов отметил, что «придется выбрать - использовать административную преюдицию или институт уголовного проступка. Одно из двух, если использовать в правоприменительной практике и то и другое, мы потеряем границы - где начинается преступление, а где административное правонарушение. Ни одна из стран не использует административную преюдицию и институт уголовного проступка одновременно» ${ }^{3}$. Следующий уголовно-правовой запрет с административной преюдицией был введен только через год (в июле 2017 г.), а спустя еще год появились три таких запрета. В частности, конструкция административной преюдиции появилась в ст. 171.4 (вве-

\footnotetext{
2 Текст документа официально опубликован не был.

${ }^{3}$ Бизнес против коррупции : станет ли преступление «уголовным проступком»? URL: https://pasmi.ru/archive/160776/ (дата обращения: 18.07.2019).
} 


\section{Вестник ВГУ. Серия: Право}

дена Федеральным законом от 26 июля 2017 г. № 203-ФЗ), 215.3 (в данной редакции статья введена Федеральным законом от 29 июля 2018 г. № 229-Ф3), 315 (ч. 1) (в указанной редакции данная часть статьи введена Федеральным законом от 2 октября 2018 г. № 348-Ф3), 282 (в данной редакции статья введена Федеральным законом от 27 декабря 2018 г. № 519-Ф3). Как долго продлится очередной этап деятельности по введению уголовно-правовых запретов с административной преюдицией покажет время.

Таким образом, необходимо констатировать, что факт наличия уголовно-правовых запретов, сконструированных с административной преюдицией, и постепенного расширения их числа в УК РФ - это существующая реальность. В доктрине уголовного права существует достаточно много предложений по использованию административной преюдиции при конструировании отдельных уголовно-правовых запретов. Возможно, расширение круга уголовно-правовых запретов с административной преюдицией постепенно нивелирует «границу» между уголовным и административным (административно-деликтным) правом и позволит со временем утвердиться концепции уголовного права в «широком» смысле. Использование конструкции административной преюдиции будет способствовать сближению административно-правовых и уголовно-правовых запретов, а в идеале - содержательному расширению их предупредительного воздействия. Однако это в теории. На практике же в этой части нередко происходит обратный эффект.

C реализацией некоторых уголовно-правовых запретов с административной преюдицией возникают существенные проблемы в правоприменительной практике. Так, положения ст. 151.1 «Розничная продажа несовершеннолетним алкогольной продукции» УК РФ должны были применяться только в случае, когда назначенное лицу административ-

๓ ное наказание по ч. 2.1 ст. 14.16 КоАП РФ не дало должного исправи-

을 тельного эфрфекта. Логично, что карательное воздействие наказания в такой ситуации должно увеличиваться. Вместе с тем, исходя из анализа 尺े правоприменительной практики ${ }^{4}$, этого не происходит. Напомним, что согласно ч. 2.1 ст. 14.16 КоАП РФ розничная продажа несовершеннолетнему алкогольной продукции, если это действие не содержит уголовно

254 наказуемого деяния, влечет наложение административного штрафа на граждан в размере от тридиати тысяч до пятидесяти тысяч рублей; на должностных лиц - от ста тысяч до двухсот тысяч рублей; на юридических лиц - от трехсот тысяч до пятисот тысяч рублей. На практике же достаточно многочисленны случаи назначения наказания в виде штрафа по ст. 151.1 УК РФ в фиксированной сумме или в размере заработной платы или иного дохода осужденного, значительно ниже, чем тридцать тысяч рублей.

${ }^{4}$ Подробнее см.: Маркунцов С. А., Одоев О. С. Назначение справедливого наказания за преступления, составы которых сконструированы с использованием административной преюдиции (на основе анализа судебной практики по ст. 151.1 УК РФ) // Уголовное право. 2016. № 3. С. 69-77. 


\section{Уголовное право. Уголовный процесс. Криминалистика}

Так, приговором и.о. мирового судьи судебного участка № 2 Первомайского района г. Ижевска от 21 декабря 2015 г. М. признана виновной в совершении преступления, предусмотренного ст. 151.1 УК РФ. Ей назначено наказание с применением ст. 64 УК РФ в виде штрафра в размере пятнадцати тысяч рублей. При этом суд, квалифицируя действия осужденной как неоднократные, отметил, что М. в пределах указанного в законодательстве срока уже привлекалась к административной ответственности по ч. 2.1 ст. 14.16 КоАП РФ, и ей был назначен административный штрафр в размере тридцати тысяч рублей ${ }^{5}$.

В ряде случаев размер уголовного штрафа был ниже размера административного штрафра за счет того, что мировые судьи назначали штраф в размере заработной платы или иного дохода осужденного.

Так, приговором мирового судьи судебного участка № 1 по Хайбуллинскому району Республики Башкортостан от 22 марта 2016 г. гражданин К. признан виновным в совершении преступления, предусмотренного ст. 151.1 УК РФ, ему назначено наказание в виде штрафа в размере заработной платы в сумме шесть тысяч девятьсот рублей. При назначении наказания суд учел, что смягчающими обстоятельствами являются признание вины, раскаяние в содеянном. К. положительно характеризуется в быту, имеет малолетнего ребенка (в данном случае ст. 64 УК РФ не применялась $)^{6}$.

На первый взгляд, такой размер уголовного штрафа является низким он в несколько раз меньше размера административного штрафа, предусмотренного для граждан санкцией ч. 2.1 ст. 14.16 КоАП РФ. Однако в данной ситуации оценка не может быть столь однозначной, вопрос здесь сложнее.

Так, если смоделировать ситуацию, когда мировой судья назначил бы осужденному К. формально наиболее строгое наказание из предусмотренных санкцией ст. 151.1 УК РФ, т. е. исправительные работы на максимально возможный срок с наибольшим размером удержания из заработной платы осужденного, т. е. на 1 год с удержанием 20 \% заработной платы, то вышло бы, что в случае исполнения такого наказания из заработной платы осужденного было бы удержано всего на 20 \% (или на 1380 рублей) больше суммы, назначенной ему согласно рассмотренному выше приговору суда, - всего 16560 рублей. При этом формально было бы назначено самое строгое из числа возможных наказание в максимальном размере.

Однако возможен вариант, при котором исправительные работы могли быть назначены на минимальный срок, предусмотренный санкцией ст. 151.1 УК РФ, т. е. на два месяца с минимально возможным процентом удержания из заработной платы осужденного (5 \%). В случае исполнения такого смоделированного приговора с осужденного было бы всего удер-

5 Сайт «Росправосудие». URL: https://rospravosudie.com/court-sudebnyjuchastok-2-pervomajskogo-rajona-g-izhevska-udmurtskoj-respubliki-s/act225102822/ (дата обращения: 20.02.2016).

6 Сайт «Росправосудие». URL: https://rospravosudie.com/court-sudebnyjuchastok-1-po-xajbullinskomu-rajonu-respubliki-bashkortostan-s/act-228622297/ (дата обращения: 20.02.2016). 


\section{Вестник ВГУ. Серия: Право}

жано 690 рублей. При этом формально осужденному было бы назначено самое строгое наказание в пределах санкции ст. 151.1 УК РФ. Насколько было бы справедливым такое наказание? Какое предупредительное воздействие оно несет? Вопросы риторические.

Приведенные примеры относятся к периоду 2015-2016 гг. Анализ статистики Судебного департамента при Верховном Суде РФ (формы № 10.3 «Отчет о видах наказания по наиболее тяжкому преступлению (без учета сложения)» и № 10.3.1 «Отчет о сроках лишения свободы и размерах штрафов (приложение к отчету формы № 10.3)») за последние годы показывает, что, на первый взгляд, ситуация с правоприменительной практикой по ст. 151.1 УК РФ стала меняться в лучшую сторону. Так, если в 2012 г. из 261 случая назначения штрафов в 139 (53\%) случаях он был менее 5 тысяч рублей, в 120 (46 \%) случаях - от 5 до 25 тысяч рублей и только в 2 случаях - выше 25 тысяч рублей. В 2013 и 2014 гг. ситуация несколько изменилась в сторону увеличения штрафов, назначаемых за совершение преступления по ст. 151.1 УК РФ, но не существенно. В эти годы штраф в размере менее 5 тысяч рублей назначался примерно в 40 и $32 \%$ случаев назначения штрафа соответственно, штраф в размере от 5 до 25 тысяч рублей - в 53 и $54 \%$ приговоров, в которых осужденный приговорен к данному виду наказания, и штраф в размере свыше 25 тысяч рублей только в 7 и 13 \% случаев соответственно 8 . В 2015 г. из 175 случаев назначения штрафа по ст. 151.1 УК РФ только в 19 (11\%) он был менее 5 тысяч рублей; в $48(27,5 \%)$ - от 5 до 25 тысяч рублей; в 108 $(61,5 \%)$ - свыше 25 тысяч рублей. В последние три года соответствующие статистические показатели стабилизировались на относительно приемлемом уровне. В 2016, 2017 и 2018 гг. соответственно из 266, 295 и 296 случаев назначения штрафра по соответствующей статье только в 5 (2\%), 9 (3\%) и 12 (4 \%) случаях (соответственно по годам) он был менее 5 тысяч рублей; в 69 (26 \%), 53 (18\%) и 59 (20\%) - от 5 до 25 тысяч рублей и, наконец, в 192 (72 \%), 233 (79 \%) и 225 (76 \%) случаях он был более 25 тысяч рублей. Одновременно растет число осужденных по ст. 151.1 УК РФ, которым назначается наиболее строгий вид наказания, предусмотренный санкцией соответствующей статьи УК РФ, - исправительные работы. Так, если ранее этот вид наказания назначался сравнительно нечасто: в 2012 г. -16 раз (5,7 \% случаев), в 2013 г. -28 раз (7,7 \%), в 2014 г. -51 раз (примерно $17 \%$ ), то в 2015 г. - 76 раз (25 \% приговоров), в 2016, 2017 и 2018 гг. соответственно 192, 197 и 195 раз, что составило примерно 34 \% приговоров. Представляется, что во многих случаях эти цифры отнюдь не свидетельствуют о существенном усилении карательного воздействия в случае неоднократного совершения розничной продажи несовершен-

\footnotetext{
${ }^{7}$ Официальный сайт Судебного департамента при Верховном Суде РФ : данные судебной статистики. URL: http://www.cdep.ru/index.php?id=79 (дата обращения: 18.07.2019).

${ }^{8}$ См.: Одоев О. С. Административная преюдиция в уголовном праве России и государств СНГ. М., 2018. С. 27.
} 


\section{Уголовное право. Уголовный процесс. Криминалистика}

нолетним алкогольной продукции. С учетом того, что в последнее время наблюдается тенденция увеличения числа приговоров по ст. 151.1 УК РФ, в которых в качестве наказания назначается либо штрафр в недиксированном размере, либо исправительные работы («штрафр в рассрочку»), необходимо устранить «рассогласованность» санкций ч. 2.1 ст. 14.16 КоАП РФ и ст. 151.1 УК РФ. Представляется вполне логичным с учетом существующих социально-экономических реалий (прежде всего, реального уровня заработных плат и доходов осужденных лиц) вывод о том, что необходимо не только скорректировать в сторону увеличения нижние и, пожалуй, верхние границы наказаний, предусмотренных санкцией ст. 151.1 УК РФ, но и дополнить санкцию данной статьи еще одним альтернативным наказанием, карательное воздействие которого не состояло бы в ограничении имущественных интересов осужденного (например, в виде обязательных работ).

Анализ статистических данных числа зарегистрированных преступлений, запреты которых сконструированы с использованием административной преюдиции, указывает на неоднозначность ситуации с правоприменительной практикой (табл.).

Т а б ли и а

Количество зарегистрированных преступлений, запреты которых сконструированы с использованием административной преюдииии, за период 2009-2017 ге.

\begin{tabular}{|c|c|c|c|c|c|c|c|c|c|}
\hline $\begin{array}{c}\text { Статьи УК РФ с } \\
\text { запретами с ад- } \\
\text { министративной } \\
\text { преюдицией }\end{array}$ & 2009 & 2010 & 2011 & 2012 & 2013 & 2014 & 2015 & 2016 & 2017 \\
\hline 178 & $\mathbf{8}^{*}$ & $\mathbf{9}$ & $\mathbf{1 3}$ & $\mathbf{5}$ & $\mathbf{9}$ & $\mathbf{9}$ & - & - & - \\
\hline 151.1 & - & - & $\mathbf{2 0}$ & $\mathbf{4 6 2}$ & $\mathbf{3 9 4}$ & $\mathbf{4 0 5}$ & $\mathbf{5 1 6}$ & $\mathbf{6 5 5}$ & $\mathbf{7 0 3}$ \\
\hline 212.1 & - & - & - & - & - & $\mathbf{0 *}$ & $\mathbf{4}$ & 0 & 0 \\
\hline 14.1 (ч. 2) & - & - & - & - & - & - & $\mathbf{6 0 4 5}$ & $\mathbf{7 3 0 4}$ & $\mathbf{8 5 3 3}$ \\
\hline 264.1 & - & - & - & - & - & - & $\mathbf{4 1 0 3 0}$ & $\mathbf{8 5 2 5 7}$ & $\mathbf{8 1 1 7 1}$ \\
\hline 284.1 & - & - & - & - & - & - & $\mathbf{0}$ & $\mathbf{0}$ & $\mathbf{0}$ \\
\hline 215.4 & - & - & - & - & - & - & - & $\mathbf{0 *}$ & $\mathbf{0}$ \\
\hline 116.1 & - & - & - & - & - & - & - & $\mathbf{6 4}$ & $\mathbf{1 7 4 2}$ \\
\hline 157 & - & - & - & - & - & - & - & $\mathbf{2 7 5 6 3 *}$ & $\mathbf{5 4 7 5 9}$ \\
\hline 158.1 & - & - & - & - & - & - & - & $\mathbf{4 6 4 *}$ & $\mathbf{9 2 5 0}$ \\
\hline 71.4 & - & - & - & - & - & - & - & - & $\mathbf{7 6}$ \\
\hline 215.3 & - & - & - & - & - & - & - & - & - \\
\hline $15($ ч. 1$)$ & - & - & - & - & - & - & - & - & - \\
\hline 282 & - & - & - & - & - & - & - & - & - \\
\hline
\end{tabular}

* - сведения по числу преступлений, которые зарегистрированы в год введения соответствующего запрета, сконструированного с использованием административной преюдиции, и которые в дальнейшем не отражают реальной картины регистрируемых преступлений по соответствующей статье УК РФ, поскольку часто это сведения не за целый календарный год. 


\section{Вестник ВГУ. Серия: Право}

Представляется, что в зависимости от особенностей правоприменительной практики все упомянутые выше уголовно-правовые запреты, сконструированные с использованием административной преюдиции, следует разделить на четыре группы. Первая группа - это так называемые «мертвые» запреты (статистика применения которых, как правило, менее 10 случаев в год и стремится к нулю). К этой группе запретов следует отнести, прежде всего, уголовно-правовые запреты, закрепленные в ст. 212.1, 215.4, 284.1 УК РФ, а также ранее конструировавшийся с использованием административной преюдиции запрет, закрепленный в ст. 178 УК РФ. Вторая группа - это уголовно-правовые запреты, имеющие значительную правоприменительную практику (исходя из числа зарегистрированных преступлений), как в их первоначальной редакции, так и после того, как они были сконструированы с использованием административной преюдиции. $K$ данной группе запретов следует отнести, прежде всего, уголовно-правовые запреты, закрепленные в ст. 157 УК РФ. До введения действующей редакции ст. 157 УК РФ, сконструированной с использованием административной преюдиции, число регистрируемых преступлений по данной статье значительно превышало аналогичные показатели за последующие два года. Так, в 2013 г. было зарегистрировано 68 967, в 2014 г. - 73 053, а в 2015 г. - уже 73800 преступлений по данной статье. Полагаем, что к обозначенной группе преступлений возможно отнести также запрет, закрепленный в ст 64.1 УК РФ, если исходить из положения о том, что она во многом схожа со ст. 211.1 УК РСФСР 1960 г. Третья - это относительно небольшая группа новых для УК РФ достаточно активно применяемых запретов (имеющих стабильную правоприменительную практику). $K$ данной группе запретов следует, прежде всего, отнести уголовно-правовые запреты, предусмотренные ст. 151.1 и ч. 2 ст. 314.1 УК РФ. Наконец, четвертая группа - это как новые, так и ранее существовавшие в рамках уголовного закона запреты, сконструированные в действующей редакции с использованием административной преюдиции, имеющие незначительную правоприменительную практику, оценить которую на современном этапе представляется затруднительным. К этой группе следует отнести все иные уголовно-правовые запреты, сконструированные с использованием административной преюдиции. В частности, это запреты, предусмотренные ст. 116.1, 158.1, 171.4, 215.3, 282, 315 (ч. 1) УК РФ. Подчеркнем, что данная классификация предложена исходя из имеющихся статистических данных по числу зарегистрированных преступлений. Выделение указанных групп является достаточно условным. Так, запрет, закрепленный в рамках ст. 215.4 УК РФ, можно отнести как к первой, так и к четвертой группе в рамках предложенной классификации. Вместе с тем даже такая схематичная классификация (группировка) уголовно-правовых запретов, сконструированных с использованием административной преюдиции, позволяет получить общее представлении об их применении.

Резюмируя все вышесказанное, необходимо отметить, что несмотря на то что уголовно-правовые запреты, сконструированные с администра- 
Уголовное право. Уголовный процесс. Криминалистика

тивной преюдицией, существуют в рамках УК РФ уже более десяти лет, практика их применения носит противоречивый характер и не дает однозначного ответа на вопрос об эффективности использования данной конструкции в рамках уголовного закона.

Наииональный исследовательский университет "Высшая школа эконолики” (г. Москва)

Маркунцов С. А., доктор юридических наук, доцент, профбессор фбакультета права; профбессор кафбедры юриспрудениии Московского городского университета управления правительства Москвы имени Ю. М. Лужкова

E-mail: smarkuntsov@hse.ru
National Research University "Higher School of Economics" (Moscow)

Markuntsov S. A., Doctor of Legal Sciences, Associate Professor, Professor of the Faculty of Law, Professor of the Department of Law of the Moscow City University of Management of the Government of Moskow named after Yu. M. Luzhkov

E-mail: smarkuntsov@hse.ru 